\title{
Analysis of the intraday effects of economic releases on the currency market
}

by Omid Rezania, Svetlozar T. Rachev, Edward Sun, Frank J. Fabozzi

No. 3 | AUGUST 2010

\section{WORKING PAPER SERIES IN ECONOMICS}

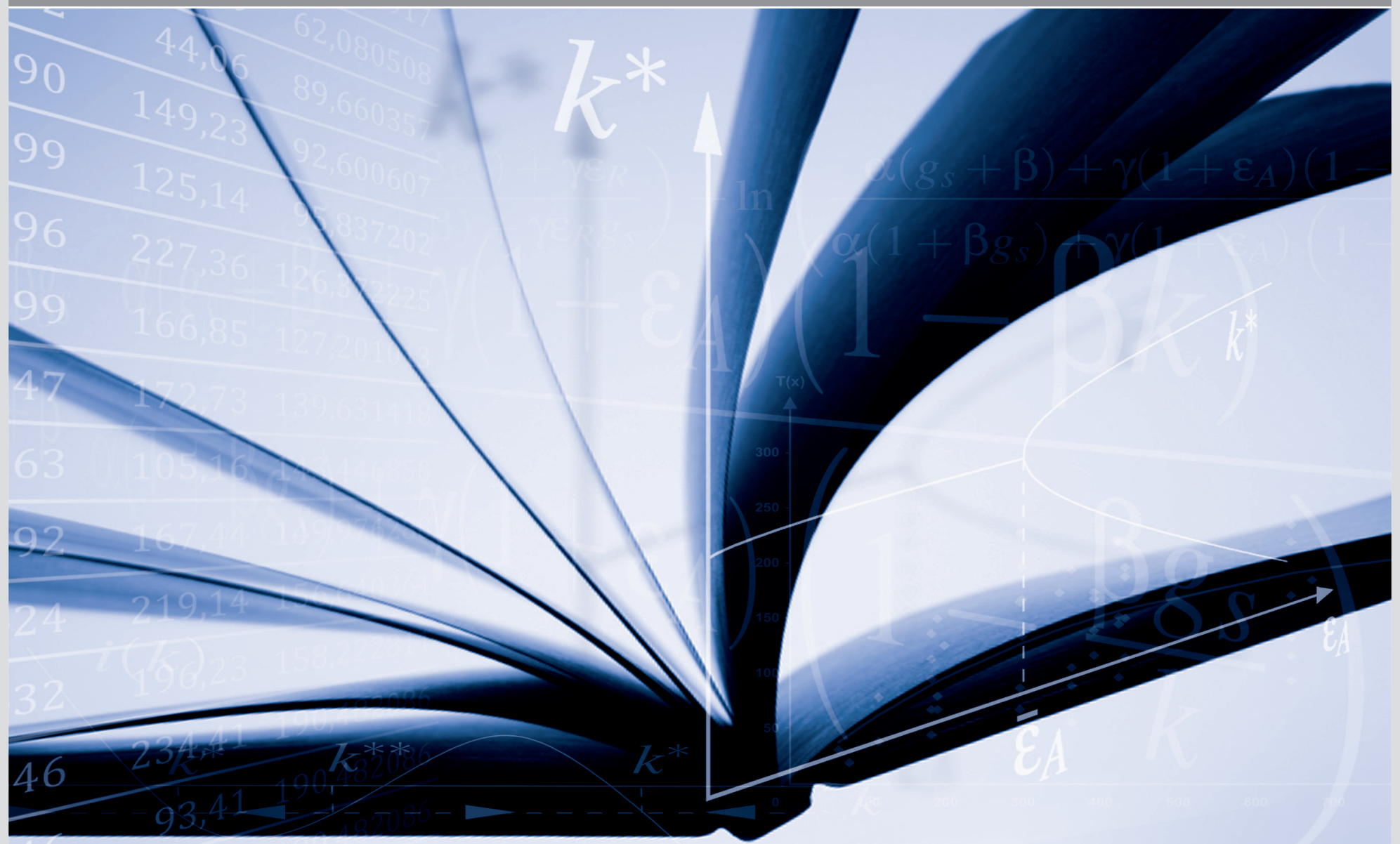




\section{Impressum}

Karlsruher Institut für Technologie (KIT)

Fakultät für Wirtschaftswissenschaften

Institut für Wirtschaftspolitik und Wirtschaftsforschung (IWW)

Institut für Wirtschaftstheorie und Statistik (ETS)

Schlossbezirk 12

76131 Karlsruhe

KIT - Universität des Landes Baden-Württemberg und nationales Forschungszentrum in der Helmholtz-Gemeinschaft

Working Paper Series in Economics

No. 3, August 2010 


\title{
Analysis of the Intraday Effects of Economic Releases on the Currency Market
}

\author{
Omid Rezania \\ School of Business Engineering \\ Karlsruhe Institute of Technology (KIT), Germany \\ Svetlozar T. Rachev \\ School of Business Engineering \\ Karlsruhe Institute of Technology (KIT), Germany \\ $\&$ \\ Department of Statistics and Applied Probability \\ University of California, Santa Barbara, USA \\ Edward Sun \\ School of Business Engineering \\ Karlsruhe Institute of Technology (KIT), Germany \\ Frank J. Fabozzi \\ Yale School of Management, USA
}

Address correspondence to Frank J. Fabozzi: Email: fabozzi321@aol.com

Rachev and Sun thank for the grants from the Deutschen Forschungsgemeinschaft (DFG). 


\begin{abstract}
$\underline{\text { Abstract }}$
Using four years of second-by-second executed trade data, we study the intraday effects of a representative group of scheduled economic releases on three exchange rates: EUR/\$, JPY/\$ and GBP/\$. Using wavelets to analyze volatility behavior, we empirically show that intraday volatility clusters increase as we approach the time of the releases, and decay exponentially after the releases. Moreover, we compare our results with the results of a poll that we conducted of economists and traders. Finally, we propose a wavelet volatility estimator which is not only more efficient than a range estimator that is commonly used in empirical studies, but also captures the market dynamics as accurately as a range estimator. Our approach has practical value in high-frequency algorithmic trading, as well as electronic market making.
\end{abstract}

Keywords: foreign exchange, volatility estimation, economic release, wavelet, high frequency.

JEL Classifications: F31, G14, G15 


\section{1._INTRODUCTION}

With the availability of high-frequency trading data, market participants are increasingly interested in understanding the effects of economic announcements. Typically to explain the volatility around releases, studies have used a micro structure approach and commonly used ARCH family models.

In comparison to the prevailing research, our contribution to the study of economic announcements on volatility is as follows. First, typically intraday research has been limited to quoted data over a period of some months and commonly for one currency only. In contrast, our dataset is the second-by-second actual executed trade data over four years in pound sterling, Japanese yen, and the euro. These three currencies traded against US dollar account for more than $80 \%$ of annual global currency trade. The data file for each currency comprise 70-80 million ticks. Each tick corresponds to one second and consists of time stamp, bid, ask and an indication of whether a trade was executed at bid or ask price. Second, unlike other studies investigating the volatility following economic announcements which use standard deviation as a volatility estimator, we use the range as a volatility estimator because previous research has shown the range to be more efficient than other estimators. Moreover, we found that range lends itself conveniently to intraday study. Third, rather than using traditional econometric tools, we use wavelets to analyze volatility around economic releases. Moreover, our use of wavelets is different from traditional wavelet applications in the sense that we use the "noise" (which is typically discarded in wavelets analysis) as our main focus, and discard the underlying "trend" in the data. Fourth, we compare the results of our analysis with the results of a poll that we conducted from major market participants. Finally, we propose a new volatility estimator using our wavelet approach and demonstrate that this estimator is on average 39 times more efficient than the range estimator and yet it does capture the dynamics of the market as reliably as the range estimator.

After providing a short review of the literature in Section 2, we describe our dataset and its construction in Section 3. In Section 4, we use regression analysis to compare the impact of various releases. We conducted a poll of head traders in major currency management firms, and chief economists in major investment banks. We asked them how they thought the economic releases affect the foreign exchange market. We 
then compared the results of the regression with the results of our poll to see how the traders and economists expectations about the foreign exchange market fit the actual market dynamics. Based on our regression analysis findings, we selected four representative economic releases to study volatility. We used the range to estimate the volatility and demonstrate a novel approach in wavelets to quantify the volatility characteristics prior and after the representative releases, and compare the results for each currency and each individual release. We then modeled the volatility clusters and volatility of volatility. A description of our empirical results follows in Section 5. In Section 6, we conclude with a summary of our findings.

\section{LITERATURE REVIEW}

\subsection{Studies on the Effects of Economic Releases}

There have been several studies that assessed the effects of economic releases on various financial markets. In Treasury markets, Balduzzi et al (2001) review the minute by minute price data from 1991 to 1995 and report an increase in volatility and bid-ask spread after the release, but a reversion to the pre-release levels within 5 to 15 minutes

after the release. Kuttner(2001) studied the effects of Federal Reserve announcements and government interventions, and observed that scheduled announcements have minimal effect on Treasury market, while surprise announcements affect the Treasury market significantly.

Dominguez and Panthanki (2007) observe that government intervention and the news of imminent government intervention (even if the intervention did not occur) had a statistically significant effect on intraday 20 minute lagged prices of the GBP/USD and JPY/USD exchange rates but not the EUR/USD exchange rate. Hasbrouck (1998) and other studies by the same author look at micro structure in the equity market and estimate volatility around various events. He observed that the market reaction varied significantly based on type of news and announcements. Edison (1997), utilizing daily foreign exchange rates to analyze the effect of various news during 1980-1995, reports that, in general, nonfarm payroll, industrial production, retail sales and unemployment have a greater effect on the exchange rates than CPI and PPI. According to Edison, there seems to be cointegration between the forecast and the release data for nonfarm payroll which is 
small yet statistically significant. Other major news did not demonstrate cointegration. Analyzing 5-minute data of the EUR/USD exchange rate for a few months in 2001, Bauwens et al.(2005) find volatility is induced by major economic releases but they did not include the most important economic release for the foreign exchange market (namely, nonfarm payroll) in their analysis.

Various studies have shown that the U.S. economic announcements are by far the most important in the world as measured by their affect on major currencies. Minor currencies (i.e. emerging market currencies as well as those of smaller economies such as New Zealand) are shown in some studies (see, for example, Kearns and Manners (2005)) to be influenced as much by their local news and announcements. James and Kasikov (2008), Kearns and Manners (2005), and Kuttner (2001) studied the effects of economic releases in foreign exchange markets and other asset classes. James and Kasikov (2008) conclude that U.S. data seem to affect major markets most consistently than other markets, while Japanese, European, and Swiss releases seem to matter least. Kasikov and Gladwin (2007) attempt to estimate market behavior given an upside surprise (i.e., an economic release which beats the market expectation) and down side surprise (i.e., an announcement which falls short of the market consensus), and claim slightly different coefficients in the linear regression for each set of surprise data.

\subsection{Applications of Wavelets}

Although wavelets have their origins in signal processing, they have found applications in many other fields ${ }^{1}$. In economics, wavelets have been utilized in analyzing business and economic cycles (see Gençay et al, 2002). When applied to financial data, they have been utilized to separate a major trend in the data from the associated noise, hence providing a clear picture of the underlying drift that can then be further analyzed.

\footnotetext{
${ }^{1}$ A wavelet is a filter which is constructed by applying a mathematical transform function (called the wavelet function) to a data series (or signal). The wavelet transform is similar to the Fourier transform with one important difference; while Fourier transforms the data into frequency space, wavelet transforms allow manipulation of the data in both time space and frequency space. A wavelet is characterized by its scale, and changing the scale allows for changing the resolution in frequency space (thus capturing the frequency effects) or time space (thus capturing the local time effects). Thus, wavelets may be adapted to best suit the signal. Various wavelet transfer functions have been developed each representing a different class of wavelets suitable for filtering different data and among these classes are Daubechies, Morlet, Haar, Symlets, and Coiflets.
} 
Capobianco (1997) applies wavelets to the daily Nikkei index to explore the volatility of returns and concludes that the GARCH effects are less prominent in the shrunken dataset and that de-noised volatility (as measured by squared returns) can estimate the latent volatility better than the original dataset. Capobianco (1999) reports success in determining intraday periodicity in returns when applying wavelets to minute by minute Nikkei index data, but does not show further utility in forecasting volatility using wavelets.

Fan and Wang (2006) use wavelets to distinguish the effect of an increase in volatility due to jumps versus the realized intraday volatility for the time series of two currencies. Setting thresholds of $10 \%$ and $20 \%$ of total volatility, they conclude that in minute data for EUR/USD and JPY/USD, for the seven months in 2004, for $20 \%$ to $40 \%$ of the days there was a jump in volatility that exceeded the thresholds. Using the universal threshold of Donoho and Johnstone (1994), Wang (1995) reports satisfactory results in identifying jumps in simulated and real data using wavelets. A clear description of the process of applying wavelets, de-noising data, and construction may be found in Keinert (2004, pp. 89-97) and Gençay et al (2002), among others.

\section{DATA DESCRIPTION}

The dataset we used in this study consists of second-by-second tick data as it appeared on two interbank electronic platforms, Reuters $3000 \mathrm{Xtra}^{\mathrm{TM}}$ and Electronic Brokerage Systems TM (EBS). These two platforms are by far the most liquid electronic platforms globally where traders can execute transactions in currency markets 24 hours a day. The two platforms are mostly accessed by market makers, but recently some investment banks allow their clients to gain access to these platforms using the banks as an intermediary.

The tick data comprise the best quotes (i.e., highest bid and lowest offer, also known as "top of the book" and tightest bid/ask spread), time stamp (including hour, minute and second), and an indication as to whether a trade was executed and at which side (i.e., if the trade was at the bid price or at ask price). The dataset include all data from January 1, 2004 to December 31, 2007 in EUR, GBP, and JPY. 
It is important to note that the dataset consists of actual prices on which trades were executed, not quoted data. Quoted data suffer from many inaccuracies, among them the fact that market makers may decide to quote a price momentarily and retrieve the quote without full intention of trading at that price. Because the volume associated with a quoted data is not known in most cases in the foreign exchange market, quoted data may at times significantly reduce the accuracy of the analysis. By restricting our dataset to actual executed trades, our study does not suffer from the inaccuracies associated with quoted data.

We used the following criteria in cleaning the data:

1. If there were no executed trades for a particular day, the data corresponding to that day was removed from the data series. This was the case with files with partial data corresponding to some weekends and some public holidays.

2. In order to remove the outliers generated by erroneous data, a percentage limit was used. If any bid or ask was larger than that percentage of the previous bid or ask, that record was assumed erroneous and removed. Various limits were used to generate data to ensure that no proper data point is inadvertently omitted. A tick was generated using interpolation from the preceding and succeeding ticks, and substituted in place of the outlier.

3. If for a single tick, bid or ask or both were missing, the past and previous ticks were interpolated and substituted in their place. If the adjacent ticks were also missing the bid or ask, an error was generated and that tick was omitted. In practice, only a handful of the latter case existed in our data.

4. Though there is informational value in the tick data with frequency that is less than one second, such data will have very little practical value to intraday trading unless the trading system is equipped with the means of sub-second execution across various electronic platforms. The success of such trading system largely depends upon the speed of execution, low latency, high-speed access to trading centers, and so on. Such issues change the nature of the trading operation to a pure engineering project where the goal is to arbitrage across various electronic platforms in micro seconds. Because this approach to the markets is not the 
subject of this paper, we ensured a maximum of one tick per second. If there was more than one tick per second, the average of bids and asks were calculated and used for that particular second.

5. If there was a second in our time series with no corresponding tick data, we generated a tick for that second by interpolating the preceding and succeeding ticks and substituting the result in place of the missing tick. Therefore, if there were multiple seconds with no corresponding data, the bids and asks thus generated would be reflective of how close or far those seconds have been from the existing adjacent records. In this way, a smoothened data series was generated.

6. We use mid price for the analysis.

\section{4._ANALYSIS}

In the first part of our analysis, we compared the effects of the most important economic releases on the exchange rate. Table 1 lists the major U.S. economic announcements. Several researchers have verified that U.S. economic releases are the most important for global currency markets and affect various exchange rates more than other local economic news. For instance, U.S. releases affect EUR/USD more than European releases affect the same currency pair (see, for instance, James and Kasikov, 2008). We therefore concentrated on US releases for our study. We apply the methodology used by Kuttner (2001) to our data in order to select a representative group of economic announcements for further analysis. In doing so, we also repeated and verified the results of James and Kasikov (2007). In this part of our analysis, we analyzed EUR/USD because it is the most liquid currency pair globally, accounting for more than a quarter of all global currency trade.

Kuttner (2001) uses an ordinary least squares (OLS) linear regression to measure the effect of the economic releases on exchange rates. We adopt this method because it is simple and reliable, sufficient number of data points (12 data points per annum for a period of four years) provides an acceptable confidence level and it can be adapted to apply to various time intervals prior to and after the release. 
The following equation indicates OLS regression of the $\log$ of the foreign exchange rate, denoted by $f x$, on surprise amount as defined below

$$
f x_{i, t+k}-f x_{i, t-1}=\alpha+\beta\left(\text { release }_{i, t}-\text { consensus }_{i, t}\right)+\varepsilon_{t}
$$

We choose to use minute data in order to avoid excessive noise. We started the data at one minute prior to the release $(t-1)$ because there is occasionally a delay in the release (sometimes up to 30 seconds). The one minute time interval allows us to pick the closest clean data to the release as possible.

Initially we defined the surprise as any announcement which deviated from the median forecast by one standard deviation. We used Bloomberg L.P. as our source for actual and forecasts of the announcement data. Though this may be the correct approach for calibrating the dynamic response base on market sentiment or similar studies, it reduces the number of data points. (For instance, based on Bloomberg ${ }^{\mathrm{TM}}$ historical data, during the period 1998-2007, there were 122 nonfarm payrolls releases but only 36 of them were more than one standard deviation away from the mean for this period.). Hence we opted to include all data and define surprise as simply the difference between the release and median of forecasts. If one were to use mean of forecasts as the consensus, it seems to make only a small difference in the case of major releases, as there is more consensus among forecasters for such releases. The median was picked in order to remove the effects of outliers.

Separately we polled the chief global economists of the following major banks: HSBC, Credit Suisse, Citigroup, Deutsche Bank, Barclays, UBS, Goldman Sachs, and Bank of America/Merrill Lynch. As a group, these banks account for more than $80 \%$ of all currency traded globally. We asked these economists to indicate (1) how important they think an economic release is for the currency market and (2) if the releases typically affects all three currencies (GBP, JPY, and EUR) equally or if a release matters more for one currency than other two.

In addition, we asked the same two questions of the head traders of the following asset management firms: Millennium Asset Management, State Street Global Advisors, Pareto Partners, Alliance Bernstein, Wellington Asset Management, BlackRock, Pacific Investment Management Company (PIMCO), and Rogge Asset Management. These asset management firms account for the majority of the currency managed globally in various 
portfolios. While the sample size is small, it does represent the most important institutional economists and traders in the currency markets. The forecasts of the economists queried in our study are widely used by market participants, and the traders in our sample asset management firms trade the largest amounts of currencies executed every day. We expected the traders' responses to be based on shorter term effects, including intraday observations of the markets, while the economist's view points to be based on economic fundamentals and long-term drivers of currency values

The results of our poll are reported in Tables 2 and 3. The most and least important releases in both tables seem to be very similar (note the shaded top and bottom rows in the tables). Furthermore, both traders and economist unanimously agree that the change in nonfarm payroll is the single most important economic release for currency markets. By comparing the poll respondents' expectations of the effects of the economic releases (as reported in the Tables 2 and 3) with the regression results (as reported in Table 4), we note that, for the most part, the two match.

In studying intraday volatility, various measures have been suggested. In the case of studying the effects of economic releases, we observe that such releases cause a jump in exchange rates, hence our measure of volatility should be able to capture such abrupt changes. Using the range (high of period minus low of period) is common among practitioners and academics. Here we define volatility as follows:

Range volatility $=$ High of period - Low of period

In comparison to other volatility estimators, we note the following:

- Compared to the close-to-close estimate, high- low range better captures the price dynamics throughout the period. The close-to-close measure may be misleading as a measure of volatility, as the close of one period may be very close to the close of the previous period, despite the fact that prices may have gyrated radically throughout the period.

- Low and high indicate the turning points in the market and as such constitute potential supports and resistance, respectively. Support and resistance possess stickiness which affects the micro dynamics of the market.

- As high and low are sticky levels (and become stickier as more market participants pay attention to them) typically large volume is traded on and around 
those levels. Therefore, the market activity may contain more information around high and lows than other times during the period.

- While $\log$ absolute returns and $\log$ squared returns as volatility estimators are not normally distributed(particularly within a high-frequency intraday timeframe), researchers have demonstrated that the log of the range has approximately normal distribution (see Yilmaz (2007).

- As a statistical estimator, range volatility is more efficient than both volatility measured by standard deviation as an estimator and close-to-close as an estimator. (See, for instance, Duque and Paxon (1997), Parkinson (1980) and Yilmaz (2007)).

- Researchers have reported higher forecasting accuracy in out-of-sample volatility estimation using range compared to some other methods including GARCH (Yilmaz (2007)).

Based on the above, we believe that range as a volatility estimator is particularly well suited to our intraday study.

\section{$\underline{4.1 \text { Volatility estimation at tick level using wavelets }}$}

For our volatility study, we selected four of the 15 economic releases. Table 4 summarizes the price move and the $t$ statistic of our regressions one hour after the release. Using this table, we selected four economic releases based on (1) the magnitude of the price change due to the release compared to other releases (as depicted by percentage price movement in Table 4) and (2) the statistical significance of the price change due to the release one hour after the release (as illustrated by the $t$ statistic of $\beta$ one hour after release in Table 4).

Nonfarm payroll is shown in our regression study to be the most important release. All of our poll respondents believed that nonfarm payroll is the most important economic release as well. Unemployment is also considered important by our respondents and shown to be influential in our regression analysis. Retail sales is a somewhat less important release, although it ranked fairly highly in our poll, and yet of lesser influence according to our regression results. Finally, we selected an economic release which is considered much less important in the foreign exchange market based on our poll results and seems to have little comparative intraday influence on exchange rates 
based on our regression results, namely the University of Michigan Consumer Confidence Survey.

For each of the above four releases, we selected six hours of tick data from three hours prior to the release to three hours after the release for JPY, EUR and GBP. To the aforementioned 12 data series, we applied various classes of wavelets and selected the appropriate wavelet based on the following: The selected wavelet should reduce the number of data points as much as possible (parsimony of the data after wavelet application), while preserving the main characteristics of the data. Moreover, the synthesized wavelet function should reflect the dynamics of the economic release. ${ }^{2}$ One class of wavelets, Daubechies wavelets, meet the above criteria better than all other wavelets. In particular, the asymmetrical form of this class of wavelets lends itself conveniently to the jump induced by the economic release, as the volatility dynamics are different after the release compared to prior to the release. Moreover exact reconstruction of the time series from the detail data series is feasible which enabled us to interpret the results in the time space.

We considered using the continuous versus discrete wavelet. Discrete analysis was preferred given that it saved space in coding (by avoiding overfitting and excessive modeling), allowed exact reconstruction, and the high resolution of tick data already provided enough information that the redundancy of continuous analysis was not needed. We applied the Daubechies wavelets to a six hour dataset. We did this for the four economic releases that we chose previously. Once the analysis was completed, we transferred the detail data back into time space in order to reconcile the results with the time of release. We modified the codes of Misiti et al(2003) for direct reconstruction of the wavelet coefficients.

Traditionally wavelets have been used in filtering out the noise from data. When wavelets are applied to time series data, the data are transformed into two data series in frequency space as follows: (1) an approximation or trend data series which captures the main underlying characteristic of the original time series and (2) a detail data series which represents the noise or local fluctuations of the original time series. Once the noise

\footnotetext{
${ }^{2}$ Wavelets simplify the analysis by reducing the number of data points. Once the analysis is performed on the reduced dataset in frequency space, the data are reconstructed (synthesized) back into time space in order to interpret the results.
} 
is removed, analysis is performed on the approximation series and results are then transformed back into time space. We took a different approach and instead of the approximation data series, we concentrated on the detail series as the latter captures the characteristics of the volatility in the time series data.

We propose a new volatility estimator using wavelets as follows. In the detail series, for each minute, we selected the second within that minute that has the highest absolute value and used that as the volatility estimator for that minute. This is similar to using the range volatility estimator. However as opposed to the range estimator which captures the difference between the high and low in time series data, our wavelet estimator is applied to the detail data series (the latter by its very definition reflects the volatility of the original time series data).

Figure 1 illustrates the range volatility series for nonfarm payroll release. Figures 2 and 3 illustrate volatility series derived from application of Daubecheis wavelets with two different scales. ${ }^{3}$ The third Daubecheis wavelet $\mathrm{DB}(3,1)$ has a lower resolution than the fifth Daubechies wavelet $(\mathrm{DB}(5.1))$ as a filter and is depicted here for illustration. Each line in the figures corresponds to one release occurrence.

Next we measured the variance of the range estimator and compared it with the variance of our wavelet estimator to see which estimator is more efficient. We defined the efficiency ratio as:

Efficiency ratio $=$ variance of range estimator/variance of wavelet estimator

Table 5 summarizes our findings. Across all three currencies and four releases, our wavelet estimator is on average 39 times more efficient than range estimator, the latter itself being a more efficient estimator than other volatility estimators. Moreover we were interested to see how our wavelet estimator compares with range estimator in capturing the dynamics of the market. To that end, we run an ordinary least square regression as follows:

$y=\alpha+\beta x$ where $x=$ Range estimation volatility series, $y=$ wavelet estimation volatility series

\footnotetext{
${ }^{3}$ The Daubecheis class of wavelets comprise Daubecheis wavelets with different scales. Increasing the scale increases the resolution, hence providing a filter which detects finer (more minute) details.
} 
The results of the regression are reported in Table 6 . In this table, we regressed the minute by minute volatility series as measured by range estimator on the minute by minute volatility series measured by our wavelet estimator. In estimating range and wavelet volatility, we have used second by second data to reach a volatility number for the each minute. We then smoothened the data sets by calculating 10 minute moving averages of range and wavelet estimation series and ran the regression again on the smoothened data. The results of the latter were highly satisfactory as regression statistics all point to a good fit. Hence our wavelet estimator clearly captures the dynamics which are captured by range estimation, while being more efficient than range estimator.

\section{$\underline{4.2 \text { Analyzing volatility clusters using wavelets }}$}

Using the second by second tick data, we calculated the minute return. We then defined a volatile minute as one in which the highest (lowest) tick was above (below) one standard deviation of the mean volatility in that minute throughout the dataset. We defined volatility clusters if two or more volatile minutes were adjacent to each other.

Figure 4 shows the time up to 360 minutes on horizontal axis and number of volatility clusters in any minute on y axis. The the economic release occurs on minute 180. As an illustration, in the Nonfarm EUR figure, at minute 120 we read 25 on the vertical axis. Therefore throughout the dataset, there have been 25 instances of volatility cluster happening at the minute 120 .

\section{$\underline{4.3 \text { Analyzing the volatility of volatility }}$}

We used second by second data to analyze the volatility of volatility. Here we used the following definition of volatility:

volatility $=\operatorname{abs}\left(\ln \frac{P_{t}}{P_{t-1}}\right)$

where $P_{t}$ represents the exchange rate at time $t$. 
We constructed volatility series to which we applied various wavelets. We selected the 5th Daubechies wavelet based on criteria discussed earlier and applied it to the volatility data series.

We defined a volatility cluster as any two or more seconds where the jump in volatility is above one standard deviation of the mean of for the corresponding minute throughout the data set. To illustrate our method, in Figure 5, we have counted (for each second) the volatility of volatility clusters in the detail data series for one day of data, and generated a line for each cluster. Nonfarm payroll number was released at second 10,800. The denser part of the spectrum corresponds to periods with higher density of volatility clusters. One can visually verify that those periods increase significantly subsequent to the release. This visual representation is indeed similar to the visualization used in signal processing known as scalograms, which would have visually represented the high frequency (corresponding to high volatility in our example) and low frequency regions( for examples of scalograms, see Ogden (1997)).

In Figure 6, the data count as above have been repeated, but for all release days of the four years of data. So for each second of the period (announcement time -3 hour to announcement time +3 hour), we have counted the volatility clusters. The announcement was made in each case at second 10,800 .

\section{5._EMPIRICAL RESULTS}

We consider a release to be important if (1) it induces a comparatively higher change in the exchange rate and (2) the change remains significant within 60 minutes of the release. In Table 4, we note that the more important the economic release, the more likely that the computed $t$ value of the regression be larger. More important economic releases not only cause a large jump in the exchange rate, but the exchange rate stays at the new levels for a longer period than the lesser economic release. The computed $t$ value decreases exponentially after the release and the exponential decay in the $t$ statistics is sharper in the case of more important news. This effect may probably be explained by the fact that market participants pay attention to the important releases, absorb the news rapidly, and thereafter the effect of the news is reduced. 
As with our survey respondents, the regression results seem to support some of their opinions but not all of them. Nonfarm payroll is the most important news in the foreign exchange market - various studies by investment banks and central banks (e.g., Clifton and Plumb, 2007) confirm this result - and the Philadelphia Fed survey is among the least important. Our respondents views' match our findings in these cases. However, both economists and traders contended that the ISM Non-Manufacturing survey is among the top five releases, but our regression results do not support this.

Participants in the currency market all agree that various themes become important for that market during some period of time, and those themes lose their significance after a while. Hence the survey results may be to some degree a reflection of what the respondents deem to be important at the time of the poll.

Regarding the volatility cluster phenomena as illustrated in Figure 4, the first peak in the volatility cluster prior to the release corresponds to an intraday market seasonality due to overlap of markets in different time zones. Ignoring that seasonality, one observes that the number of volatility clusters increases as the time of the release is approached. The volatility clusters jump to their local high at or immediately after the release, and decline sharply afterwards. Starting with three hours prior to the release, we notice that the more important the release, the less the number of the volatility clusters in the first few minutes of the three hour period for all currencies. Moreover, the more important the economic release, the higher the jump at the release time. Finally, as can be seen in Table 7, the more important economic releases seem to lead to a faster decline in volatility in the three hours following the release than the lesser economic data.

We demonstrated that nonfarm payroll and unemployment are the most important of the four releases selected, followed by retail sales and then the University of Michigan survey. On the days that market participants are expecting an important economic release, in the absence of other volatility inducing events, on average, they become less active in the market. This leads to the low volatility cluster phase at the starting minutes of the three-hour period prior to the release. After the release, volatility cluster decays faster in case of more important economic release. This is also intuitive, as market participants pay attention to important releases, and hence absorb the economic release rapidly. In the case of a less important economic release, the jump in volatility is less 
and, because fewer participants pay attention to it, the volatility clustering behavior does not change materially subsequent to the release.

We performed a Wald-Wolfowitz runs test (simply runs test hereafter) to evaluate the hypothesis as to whether the sequence of volatility clusters is randomly distributed. (Note that the number of data points differs from one release to the other.) On the vast majority of release days, the hypothesis that volatility clusters occur randomly is rejected with $95 \%$ statistical significance. The ratio of the minutes after the release to minutes before the release in which the random distribution of volatility clusters can be rejected is reported in Table 8. In that table we also observe that

- For all releases and all currencies, there are more than or equal instances of rejecting the hypothesis after the release than prior to the release. In other words, the release tends to increase the likelihood of non-random clustering of volatile minutes.

- The more important the economic release, the more likely it is that the post release clusters are non-random.

- The more important the economic release, the higher the ratio of post to prior nonrandom days. In other words, the more important economic releases are more likely to introduce a non-random volatility inducing effect into the market.

- The non-random likelihood of distribution is most noticeable in the euro followed by the British pound and Japanese yen.

In Figure 7 we compare the volatility clusters for the 4 selected releases and we can draw the following conclusions:

- The number of volatility clusters increases after all releases, but it increases significantly more for more important releases (nonfarm and unemployment) followed by retails sales, and finally the least important economic release (the University of Michigan survey). Hence the more important the economic release, the more likely it is for the market to become volatile after the release and for volatility to cluster subsequent to the release.

- Except in the case of the University of Michigan survey, Japanese yen has the highest tendency to show volatility clustering, followed by the British pound and then the euro. Because the University of Michigan survey is the least important of the 
releases analyzed, the Japanese yen volatility behavior may be the results of traders' preference for using this currency as a means of short intraday trading.

Figure 8 compares the volatility cluster results between currencies and between the four releases. Except for the least important release, the number of cluster minutes increases after the release.

The anomaly observed for the University of Michigan Consumer Confidence Survey is worth considering. Based on the results for both the runs test and volatility cluster analysis, it seems that this least important release is not significant in changing the likelihood of volatility clustering. One possible explanation may be that on the days that market participants are expecting important announcements, the market is cautious prior to the release. Volatile behavior may not continue as market participants may take the opposite side of a trade, or not participate at all. Subsequent to the release, market participants absorb the information in the economic release, witness the initial surge in activity in the immediate vicinity of the release, and may be forced to reduce or increase their positions based on the release. This would lead to higher trade volume and, if some of these trades which are initiated by various market participants coincide or are executed with little time in between, may increase volatility clustering.

Our empirical results thus far suggest that the majority of the economists and traders polled in our survey were incorrect in contending that the effect of the release is the same for all three major currency exchange rates. Figure 7 clearly shows that Japanese yen seems to be affected more and demonstrates a higher likelihood of volatility clustering than the euro and the British pound.

As indicated in Figure 6, we observe the following about volatility of volatility:

- It is lower prior to the more important releases.

- The jump is higher from the pre-release to post-release levels for more important announcements.

- It decreases after the release, with occasional peaks still observable.

In order to model the behavior of the volatility of volatility, we smoothed the secondby-second data. The results for the three currencies and four releases are summarized in Table 9. In all cases, we found exponential decay to be the good fit for the data points after the release. 


\section{6._CONCLUSIONS}

We propose a new volatility estimator based on wavelet analysis and demonstrate that this wavelet estimator is 39 times more efficient than the measure commonly used, range estimator. Moreover, by performing an OLS regression on the results of range volatility estimation and our wavelet volatility estimation, we demonstrate a very good fit suggesting that our estimation method successfully captures the dynamics of the market as accurately as a range estimator. We establish that for three currencies and with four representative economic releases, the volatility clusters occur prior and post release. However the likelihood of occurrence of clusters increases significantly after the release compared to prior to the release, and the likelihood decreases exponentially subsequent to the release. The likelihood of clustering of volatility of volatility also decreases exponentially after the release. This may be explained by the fact that traders were watching the market carefully in anticipation of an important release, rapidly absorb the information in the release, and act upon it in a short time. This urgency to react to the release does not exist in the case of less important releases, hence the slower decay and lesser concentration of volatility clusters.

We further demonstrated that the volatility clusters occur more frequently for the Japanese yen, followed by the pound sterling and euro. We also show that the arrival of volatility clusters is not random, and the nonrandomness increases significantly after the release. However, the rate of decay is not the same with all four releases, and the most important releases decay faster than less important ones. 


\section{REFERENCES}

Balduzzi, P., Elton, E. J., and T. Clifton Green (2001). "Economic News and Bond Prices: Evidence from the US Treasury Market," Journal of Financial and Quantitative Analysis, 36 (4): 523-543.

Bauwens, L.,Omrane, W.B. and P. Giot (2005). "News Announcements, Market Activity and Volatility In Eur/Dollar Foreign Exchange Market," Journal of International Money and Finance, 24(7): 1108-1125.

Capobianco, E. (1999). “Wavelets for High Frequency Financial Time Series,” Institute of Mathematical Modeling, Technical University of Denmark.

Capobianco, E. (1997). “Wavelet De-noised Financial Time Series,” presented at International Workshop on Stochastic Model Building and Variable Selection, Duke University.

Clifton, K. and M. Plumb (2007). "Intraday Currency Market Volatility and Turnover," Bulletin, International Department, Reserve Bank of Australia: 1-9.

Dominguez, K.M.E. and F. Panthaki (2007). "The Influence of Actual and Unrequited Interventions," International Journal of Finance and Economics, 12: 171-200.

Donoho, D.L and I.M. Johnstone (1994), "Ideal De-noising in An Orthonormal Basis Chosen From A Library Of Bases," CRAS Paris, Series I, 319: 1317-1322.

Duque, J. L. C. and D. A. Paxson (1997). "Empirical Evidences on Volatility Estimators," Working Paper, Cadernos de Económicas, Documento de Trabalho n. ${ }^{\circ}$ 5/97, Departamento de Gestão, ISEG - Instituto Superior de Economia e Gestão, Universidade Técnica de Lisboa, ISSN N. 0874-8470.

Edison, H.J. (1997). “The Reaction of Exchange Rates and Interest Rates to News Releases," International Journal of Finance and Economics, 2: 87-100.

Fan, J. and Y. Wang (2006). "Technical Report As Supplemental Material: Multi-Scale Jump and Volatility Analysis For High Frequency Financial Data." Available at SSRN http://ssrn.com/abstract $=957607$.

Gençay, R., F. Selçuk, and B. Whitcher (2002). An Introduction to Wavelets and Other Filtering Methods in Finance and Economics, Academic Press: New York.

Hasbrouck, J. (1998). "Security Bid/Ask Dynamics with Discreteness and Clustering: Simple Strategies for Modeling and Estimation," Working Paper, New York University Stern School of Business. 
James, J. and K. Kasikov (2008). "Impact Of Economic Data Surprises On Exchange Rates In The Inter-Dealer Market," Quantitative Finance, 8 (1): 5-15

Kasikov K., and P. Gladwin (2007). "Intraday Volume and Volatility of Exchange Rates," Citifx Currency Advisor, Investor Edition, No. 27.

Kearns, J. and P. Manners (2005). "The Impact Of Monetary Policy On The Exchange Rate: A Study Using Intraday Data," Research Discussion Paper, Economic Research Department, Reserve Bank of Australia, 2005-02.

Keinert, F. (2004). Wavelets and Multiwavelets, Chapman and Hall/CRC.

Kuttner, K. N. (2001). "Monetary Policy Surprises And Interest Rates: Evidence From The Fed Funds Futures Market," Journal of Monetary Economics, 47(3): 523-544.

Misiti M., Y. Misiti, G. Oppenheim, and J.M. Poggi (2003). Les Ondelettes et Leurs Applications, Hermes, UK.

Ogden, R.T. (1997). Essential Wavelets for Statistical Applications and Data Analysis, Birkhauser, USA.

Wang, Y. (1995). “Jump and Cusp Detection By Wavelets,” Biometrika, 82 (2): 385-397.

Yilmaz, F. (2007). "Fighting Volatility with Sticks and Stones," Global Foreign Exchange, Bank of America Monograph Series: Number 248. 


$\begin{array}{ll}\text { University of Michigan Consumer Confidence } & 15: 00 \\ \text { Institute of Supply Management ( ISM) Index : Manufacturing } & 15: 00 \\ \text { Institute of Supply Management ( ISM) Index : Non- Manufacturing } & 15: 00 \\ \text { Philadelphia Fed report } & 15: 00 \\ \text { New Home Sales } & 15: 00 \\ \text { Conference Board Consumer Confidence } & 15: 00 \\ \text { Chicago Purchasing Managers Index } & 15: 00 \\ \text { Treasury International Capital System ( TIC) Flow of Funds } & 14: 00 \\ \text { Industrial Production } & 14: 15 \\ \text { Durable Goods Orders } & 13: 30 \\ \text { GDP, QoQ Annualized } & 13: 30 \\ \text { Core CPI } & 13: 30 \\ \text { Trade Balance } & 13: 30 \\ \text { Empire Manufacturing Index } & 13: 30 \\ \text { Housing Starts } & 13: 30 \\ \text { Unemployment Rate } & 13: 30 \\ \text { Change in Non-farm payrolls } & 13: 30 \\ \text { Retail Sales Less Autos } & 13: 30\end{array}$

Table 1. Major US economic releases. All economic release data were obtained from Bloomberg L.P. 


\begin{tabular}{|c|c|c|c|c|c|}
\hline Economist respondents & \begin{tabular}{|l} 
very \\
important
\end{tabular} & \begin{tabular}{|l|} 
moderately \\
important
\end{tabular} & \begin{tabular}{|l|} 
not \\
important
\end{tabular} & \begin{tabular}{|l} 
affects all 3 \\
currencies equally
\end{tabular} & $\begin{array}{l}\text { affects one currency } \\
\text { more than other } 2\end{array}$ \\
\hline Change in non-farm payrolls & $100 \%$ & $0 \%$ & $0 \%$ & $75 \%$ & $25 \%$ \\
\hline ISM Manufacturing & $75 \%$ & $25 \%$ & $0 \%$ & $63 \%$ & $38 \%$ \\
\hline Retail sales less autos & $75 \%$ & $25 \%$ & $0 \%$ & $75 \%$ & $25 \%$ \\
\hline GDP, QoQ annualised & $50 \%$ & $38 \%$ & $13 \%$ & $75 \%$ & $13 \%$ \\
\hline ISM Non-manufacturing & $25 \%$ & $50 \%$ & $13 \%$ & $50 \%$ & $38 \%$ \\
\hline Core CPI & $25 \%$ & $38 \%$ & $38 \%$ & $63 \%$ & $25 \%$ \\
\hline Housing Starts & $25 \%$ & $38 \%$ & $50 \%$ & $50 \%$ & $25 \%$ \\
\hline Univ. Michigan consumer confidence & $13 \%$ & $75 \%$ & $13 \%$ & $63 \%$ & $38 \%$ \\
\hline New Home Sales & $13 \%$ & $50 \%$ & $38 \%$ & $50 \%$ & $38 \%$ \\
\hline Industrial Production & $13 \%$ & $63 \%$ & $25 \%$ & $63 \%$ & $25 \%$ \\
\hline Trade Balance & $13 \%$ & $50 \%$ & $38 \%$ & $50 \%$ & $25 \%$ \\
\hline
\end{tabular}

Table 2. Poll results of chief/global economists in eight largest global investment banks. Respondents were asked whether they believed that an economic release is important for foreign exchange market, and if the economic release affects EUR/\$, JPY/\$ and GBP/\$ equally. 


\begin{tabular}{|c|c|c|c|c|c|}
\hline Trader respondents & $\begin{array}{l}\text { very } \\
\text { important }\end{array}$ & $\begin{array}{l}\text { moderately } \\
\text { important }\end{array}$ & \begin{tabular}{|l} 
not \\
important
\end{tabular} & \begin{tabular}{|l} 
affects all 3 \\
currencies equally
\end{tabular} & $\begin{array}{l}\text { affects one currrency } \\
\text { more than the other } 2\end{array}$ \\
\hline ISM Manufacturing & $75 \%$ & $25 \%$ & $0 \%$ & $63 \%$ & $38 \%$ \\
\hline Retail sales less autos & $63 \%$ & $25 \%$ & $13 \%$ & $63 \%$ & $38 \%$ \\
\hline Unemployment rate & $50 \%$ & $50 \%$ & $0 \%$ & $75 \%$ & $25 \%$ \\
\hline GDP, QoQ annualised & $38 \%$ & $63 \%$ & $0 \%$ & $75 \%$ & $25 \%$ \\
\hline New Home Sales & $13 \%$ & $88 \%$ & $0 \%$ & $88 \%$ & $25 \%$ \\
\hline Chicago PMI & $13 \%$ & $63 \%$ & $25 \%$ & $75 \%$ & $13 \%$ \\
\hline Industrial Production & $13 \%$ & $88 \%$ & $0 \%$ & $75 \%$ & $25 \%$ \\
\hline Durable Goods Orders & $13 \%$ & $63 \%$ & $25 \%$ & $63 \%$ & $38 \%$ \\
\hline Core CPI & $13 \%$ & $38 \%$ & $0 \%$ & $75 \%$ & $25 \%$ \\
\hline Empire Manufacturing & $13 \%$ & $38 \%$ & $50 \%$ & $63 \%$ & $25 \%$ \\
\hline
\end{tabular}

Table 3. Poll results of chief/head traders in the eight largest global currency management firms. Respondents were asked whether they believe that an economic release is important for foreign exchange market, and if the economic release affects EUR/\$, JPY $/ \$$ and $\mathrm{GBP} / \$$ equally. 


\begin{tabular}{|lcc|}
\hline \multicolumn{1}{|c}{ Economic Release } & $\begin{array}{c}\text { \% change in } \\
\text { EUR/USD one } \\
\text { hour after } \\
\text { release }\end{array}$ & $\begin{array}{c}\text { Statistic one } \\
\text { hour after } \\
\text { release }\end{array}$ \\
Change in Non-farm Payrolls & -0.3 & -6 \\
Institute of Supply Management Index: Manufacturing & -5.4 \\
Trade Balance & -0.2 & -4.7 \\
Unemployment Rate & -0.15 & -0.9 \\
Treasury International Capital System(TIC) Flow of Funds & -0.13 \\
Empire Manufacturing Index & -0.1 & -1.8 \\
Retail Sales Less Autos & -0.1 & -2 \\
GDP Quarterly Growth & -0.9 & -2.8 \\
Conference Board Consumer Confidence & -0.8 \\
Industrial Production & -4.5 \\
Durable Goods Orders & -0.06 \\
Chicago Purchasing Manager Index(PMI) & -0.04 \\
Philadelphia Fed Business Outlook Survey & -0.04 \\
Housing Starts & -0.04 \\
Institute of Supply Management Index: Non-Manufacturing & -2 \\
Core CPI & -0.04 \\
New Home Sales & -0.03 \\
Univ. of Michigan Consumer Confidence & -1 \\
\hline
\end{tabular}

Table 4. Regression results of lower level of equation $f x_{i, t+k}-f x_{i, t-1}=\alpha+\beta$ (release $_{i, t}-$ consensus $\left._{i, t}\right)+\varepsilon_{t}$.

The left hand side of equation is the difference in log of exchange rates one hour after the release and log of exchange rate one minute prior to the release. $t$ statistic is that of $\beta$. 


\begin{tabular}{|lccc|}
\hline \multicolumn{4}{|c|}{$\begin{array}{c}\text { E fficiency ratios (variance of range es timator/variance of wavelet } \\
\text { es timator) }\end{array}$} \\
Nonfarm Payroll & J PY & E UR & G B P \\
Retail S ales & 43.1 & 49.7 & 36.5 \\
Unemployment & 31.5 & 44.8 & 29.3 \\
Univ. Michigan survey & 43.3 & 55.4 & 28.3 \\
\hline
\end{tabular}

Table 5. Comparison of efficiency of wavelet volatility estimator and range volatility estimator. Range volatility estimator is the range of the exchange rate for each minute. Wavelet volatility estimator is based on the detail data series obtained by applying 5 th Daubechies wavelet to the exchange rate time series. 


\begin{tabular}{|c|c|c|c|c|c|c|c|c|c|c|}
\hline \multirow[b]{2}{*}{ J PY S tatistics } & \multicolumn{5}{|c|}{ Minute by minute data regression results } & \multicolumn{5}{|c|}{$\begin{array}{l}\text { Ten minute moving average regression results } \\
\text { OLS MA }\end{array}$} \\
\hline & $\begin{array}{l}\text { OLS R- } \\
\text { squared }\end{array}$ & $\begin{array}{l}\text { OLS mean } \\
\text { residuals }\end{array}$ & OLS MSE & $\begin{array}{l}\text { OLS t- } \\
\text { s tatisic }\end{array}$ & $\begin{array}{l}\text { OLS t- } \\
\text { statis ic }\end{array}$ & $\begin{array}{l}\text { OLS MA R- } \\
\text { s quared }\end{array}$ & $\begin{array}{l}\text { mean } \\
\text { residuals }\end{array}$ & $\begin{array}{l}\text { OLS MA } \\
\text { MSE }\end{array}$ & $\begin{array}{l}\text { OLS MA t- } \\
\text { statis tic }\end{array}$ & $\begin{array}{l}\text { OLS MA t- } \\
\text { s tatis tic }\end{array}$ \\
\hline Nonfarm Payroll & $8.1 \%$ & $-5.6 \mathrm{E}-13$ & $9.7 \mathrm{E}-11$ & 12.1 & 5.4 & $59.5 \%$ & $-1.3 \mathrm{E}-13$ & $1.4 \mathrm{E}-11$ & 14.2 & 23.7 \\
\hline Retail S ales & $3.3 \%$ & $-8.2 E-13$ & $5.4 \mathrm{E}-11$ & 12.9 & 3.1 & $42.3 \%$ & $-5.6 \mathrm{E}-13$ & $8.1 \mathrm{E}-12$ & 11.9 & 16.5 \\
\hline $\begin{array}{l}\text { Unemployment } \\
\text { Univ. Michigan }\end{array}$ & $8.2 \%$ & $-6.8 E-13$ & $1.1 \mathrm{E}-10$ & 11.9 & 5.5 & $60.1 \%$ & $-1.5 E-13$ & $1.6 \mathrm{E}-11$ & 13.9 & 23.8 \\
\hline s urvey & $6.1 \%$ & $-3.3 E-10$ & $2.4 \mathrm{E}-05$ & 12.2 & 4.5 & $55.3 \%$ & $-1.4 \mathrm{E}-10$ & $3.5 E-06$ & 8.7 & 22.0 \\
\hline
\end{tabular}

\begin{tabular}{|c|c|c|c|c|c|c|c|c|c|c|}
\hline \multirow[b]{2}{*}{ EUR $S$ tatistics } & \multicolumn{5}{|c|}{ Minute by minute data regression results } & \multicolumn{5}{|c|}{$\begin{array}{c}\text { Ten minute moving average regression results } \\
\text { OLS MA }\end{array}$} \\
\hline & $\begin{array}{l}\text { OLS R- } \\
\text { squared }\end{array}$ & $\begin{array}{l}\text { OLS mean } \\
\text { residuals }\end{array}$ & OLS MSE & $\begin{array}{l}\text { OLS t- } \\
\text { statisic }\end{array}$ & $\begin{array}{l}\text { OLS t- } \\
\text { statis ic }\end{array}$ & $\begin{array}{l}\text { OLS MA R- } \\
\text { s quared }\end{array}$ & $\begin{array}{l}\text { LS MA } \\
\text { ean } \\
\text { siduals }\end{array}$ & $\begin{array}{l}\text { OLS MA } \\
\text { MSE }\end{array}$ & $\begin{array}{l}\text { OLS MA t- } \\
\text { statis tic }\end{array}$ & $\begin{array}{l}\text { OLS MA t- } \\
\text { statis tic }\end{array}$ \\
\hline Nonfarm Payroll & $11.6 \%$ & $-2.6 \mathrm{E}-12$ & $-2.6 \mathrm{E}-12$ & 8.8 & 6.7 & $69.7 \%$ & $6.9 E-13$ & $1.1 \mathrm{E}-09$ & 6.1 & 29.8 \\
\hline Retail S ales & $7.6 \%$ & $-2.7 E-12$ & $2.1 \mathrm{E}-09$ & 10.9 & 5.2 & $61.3 \%$ & $2.1 \mathrm{E}-13$ & $3.2 \mathrm{E}-10$ & 6.5 & 24.8 \\
\hline $\begin{array}{l}\text { Unemployment } \\
\text { Univ. Michigan }\end{array}$ & $9.4 \%$ & $-6.1 \mathrm{E}-13$ & $7.6 \mathrm{E}-11$ & 11.9 & 5.9 & $66.7 \%$ & $-2.1 \mathrm{E}-13$ & 8.7E -12 & 17.3 & 27.5 \\
\hline s urvey & $5.1 \%$ & $-4.4 \mathrm{E}-13$ & $4.1 \mathrm{E}-11$ & 14.0 & 4.1 & $48.2 \%$ & $-2.4 \mathrm{E}-13$ & $5.8 \mathrm{E}-12$ & 16.7 & 18.8 \\
\hline
\end{tabular}

\begin{tabular}{|c|c|c|c|c|c|c|c|c|c|c|}
\hline \multirow[b]{2}{*}{ G B P S tatis tics } & \multicolumn{5}{|c|}{ Minute by minute data regression results } & \multicolumn{5}{|c|}{$\begin{array}{c}\text { Ten minute moving average regression results } \\
\text { OLS MA }\end{array}$} \\
\hline & $\begin{array}{l}\text { OLS R- } \\
\text { squared }\end{array}$ & $\begin{array}{l}\text { OLS mean } \\
\text { residuals }\end{array}$ & OLS MSE & $\begin{array}{l}\text { OLS t- } \\
\text { statisic }\end{array}$ & $\begin{array}{l}\text { OLS t- } \\
\text { statis ic }\end{array}$ & $\begin{array}{l}\text { OLS MA R } \\
\text { squared }\end{array}$ & $\begin{array}{l}\text { - mean } \\
\text { residuals }\end{array}$ & $\begin{array}{l}\text { OLS MA } \\
\text { MSE }\end{array}$ & $\begin{array}{l}\text { OLS MA t- } \\
\text { s tatis tic }\end{array}$ & $\begin{array}{l}\text { OLS MA t- } \\
\text { statis tic }\end{array}$ \\
\hline Nonfarm Payroll & $8.3 \%$ & $-5.5 E-13$ & $1.4 \mathrm{E}-10$ & 10.1 & 5.4 & $62.0 \%$ & $-1.4 \mathrm{E}-13$ & $2.2 \mathrm{E}-11$ & 9.5 & 25.3 \\
\hline Retail S ales & $3.9 \%$ & $-5.1 E-12$ & 4.1E -09 & 12.2 & 3.3 & $47.1 \%$ & $-2.4 \mathrm{E}-12$ & $6.4 \mathrm{E}-10$ & 8.5 & 18.5 \\
\hline $\begin{array}{l}\text { Unemployment } \\
\text { Univ. Michigan }\end{array}$ & $5.4 \%$ & $-6.1 E-12$ & $7.4 \mathrm{E}-09$ & 11.7 & 4.1 & $52.7 \%$ & $-3.2 E-12$ & $1.1 \mathrm{E}-09$ & 8.2 & 20.7 \\
\hline survey & $9.4 \%$ & $-6.1 \mathrm{E}-12$ & $1.2 \mathrm{E}-08$ & 9.7 & 5.9 & $66.0 \%$ & $-1.1 E-12$ & $1.8 \mathrm{E}-09$ & 6.4 & 27.6 \\
\hline
\end{tabular}

Table 6. Regressions results of range volatility estimator and wavelet volatility estimator. Note that over a moving 10 minute period and after smoothing the data, there is a good fit between the range and wavelet estimations of volatility. 


\begin{tabular}{|lccc|}
\hline & E UR & G B P & J PY \\
Nonfarm Payroll & 0.049 & 0.035 & 0.028 \\
Retail S ales & 0.045 & 0.034 & 0.025 \\
Unemployment & 0.021 & 0.018 & 0.013 \\
Univ. Michigan survey & 0.016 & 0.026 & 0.026 \\
\hline
\end{tabular}

Table 7. Decay rate of volatility clusters. A volatile minute is a minute where the volatility is at least one standard deviation higher than the mean volatility for that minute in the exchange rate time series. Volatility cluster is defined when two volatile minutes are adjacent to each other. Decay rate is $\alpha$ in the following differential equation:

$$
d N / d t=-\alpha N
$$

where $N$ is the number of volatility clusters at time $t$.

Note that the likelihood of volatility clusters decrease at a slightly faster rate in case of more important releases with the exception of the University of Michigan survey. 


\begin{tabular}{|lccc|}
\hline & E UR & G B P & J PY \\
Nonfarm payroll & 1.22 & 1.18 & 0.99 \\
Unemployment & 1.26 & 1.25 & 1.13 \\
Retail S ales & 1.22 & 1 & 1.03 \\
Univ. of Michigan survey & 0.99 & 1.01 & 1.01 \\
\hline
\end{tabular}

Table 8. Results of Wald Wolfowitz Runs Test. The numbers are the ratio of instances when the volatility clusters are non random prior to the release to instances when volatility clusters are nonrandom subsequent to the release. Note that the likelihood of nonrandom distribution of volatility clusters increases in almost all cases after the release. 


\begin{tabular}{|lccc|}
\hline & EUR & G B P & J PY \\
Nonfarm payroll & 0.015 & 0.028 & 0.027 \\
Unemployment & 0.021 & 0.021 & 0.02 \\
Retail S ales & 0.012 & 0.018 & 0.011 \\
Univ. of Michigan survey & 0.013 & 0.021 & 0.023 \\
\hline
\end{tabular}

Table 9. Decay rate of volatility of volatility clusters. A volatile minute is a minute where the volatility is at least one standard deviation higher than the mean volatility for that minute in the exchange rate time series. Volatility cluster is defined when two volatile minutes are adjacent to each other. Decay rate is $\alpha$ in the following differential equation:

$$
d N / d t=-\alpha N
$$

where $N$ is the number of volatility of volatility clusters at time $t$.

The higher up in the table the release is, the more important the release as measured by its effect on currency market. Note that generally the likelihood of occurrence of volatility of volatility clusters decreases at a slightly faster rate in case of more important releases. 


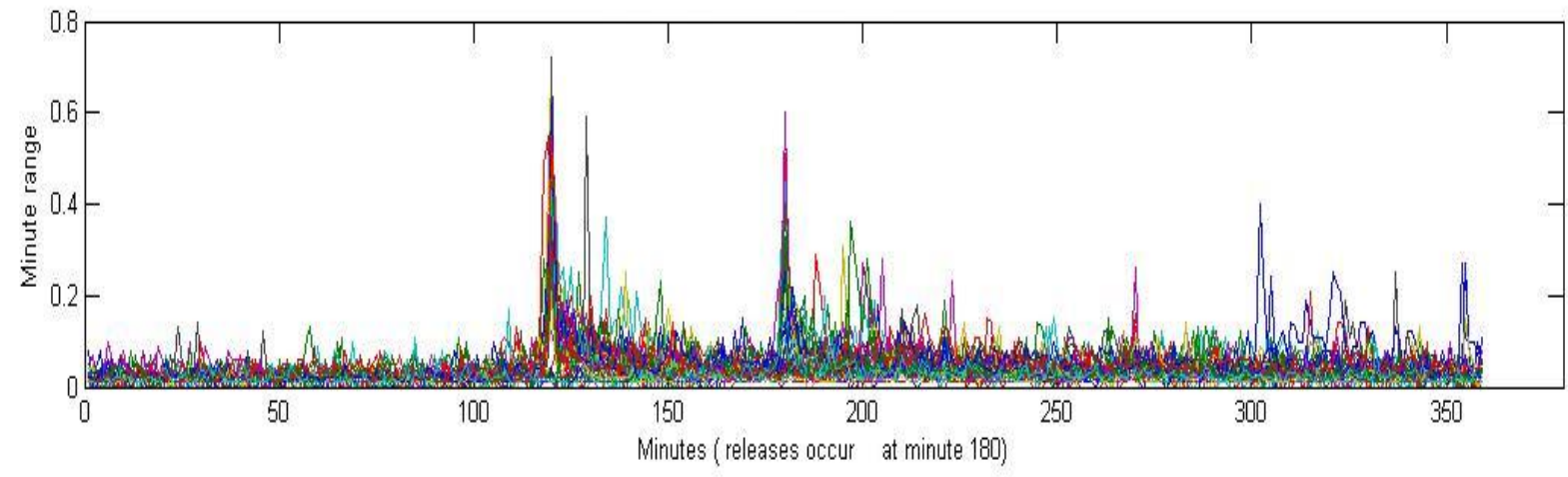

Figure 1. Range volatility estimation for JPY for nonfarm payroll releases. The first peak in volatility corresponds to overlap of markets in different time zones. The peak around minute 180 corresponds to the nonfarm payroll release. Each line corresponds to one instance of the release in our four years of tick data. 


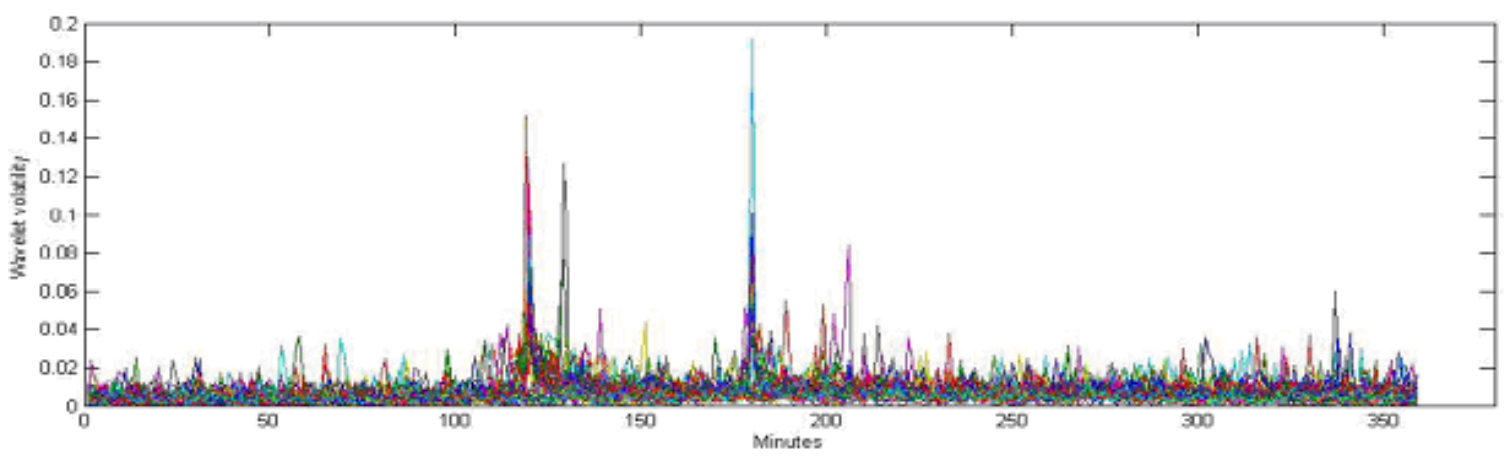

Figure 2. Minute by minute volatility estimation using 3rd Daubechies wavelet. The nonfarm payroll release is at minute 180 . Each line corresponds to one instance of the release in our four years of tick data for JPY/USD. Note the similarity of this figure with Figure 1. 


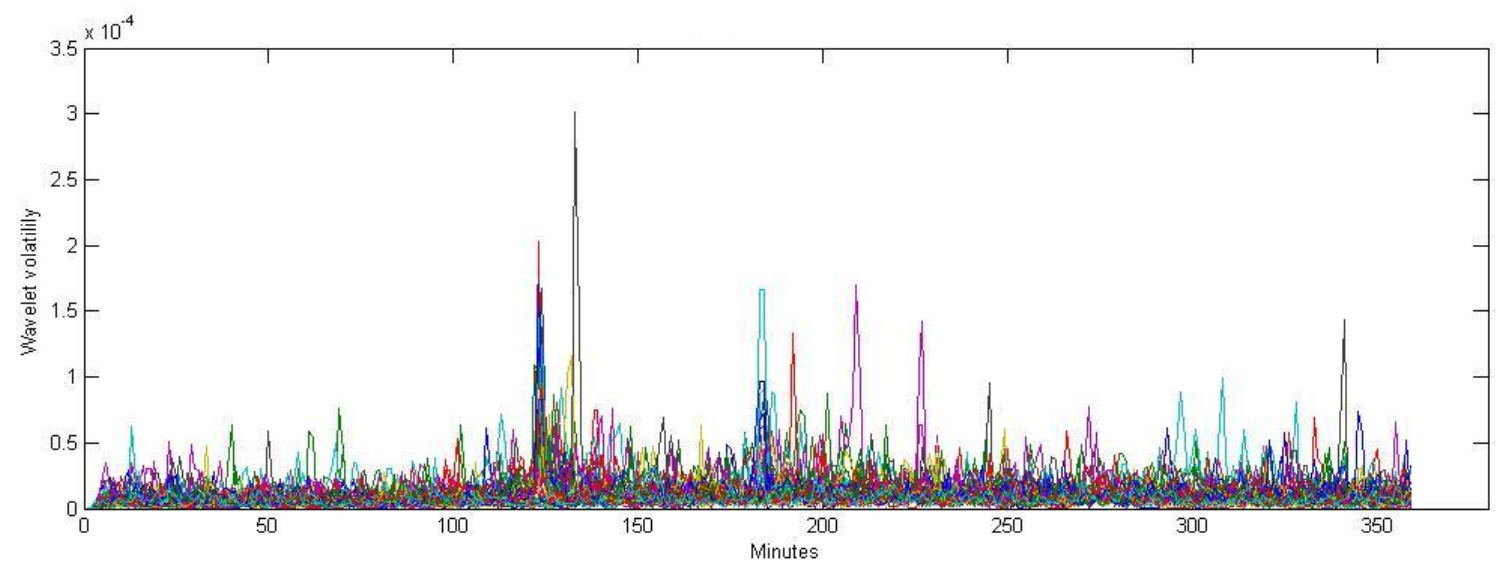

Figure 3. Minute by minute volatility estimation using 5th Daubechies wavelet. The nonfarm payroll release is at minute 180. Each line corresponds to one instance of the release in our four years of tick data for JPY/USD. Note that the 5th Daubechies wavelet reveals more minute detail compared to 3rd Daubechies wavelet in Figure 2. 

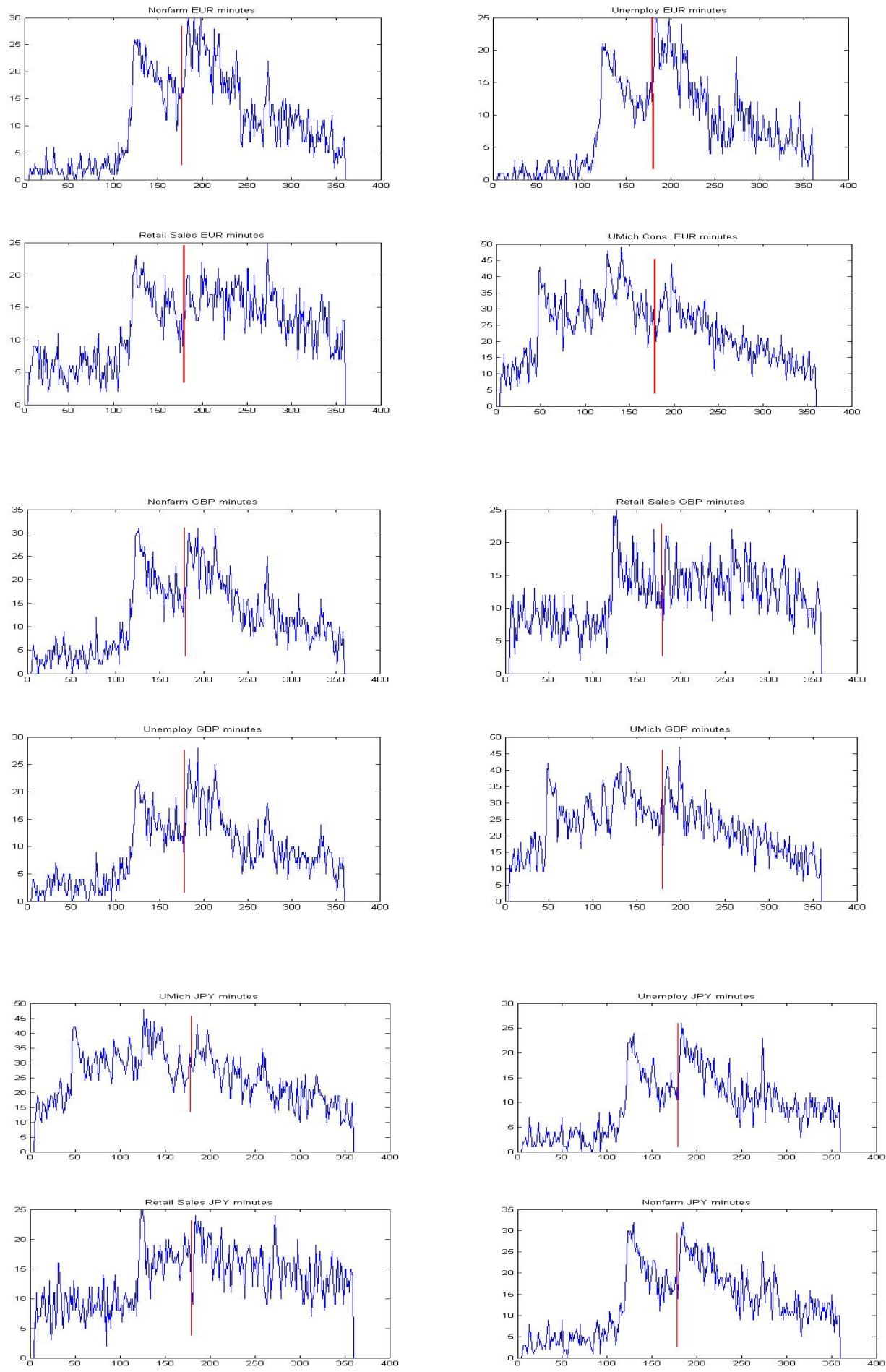

Figure 4. Volatility clusters for EUR/USD, JPY/USD and GBP/USD (vertical axis is the number of minutes with volatility cluster; horizontal axis is the time in minutes starting three hours prior to release to three hours after the release. The release is at minute 180 . 


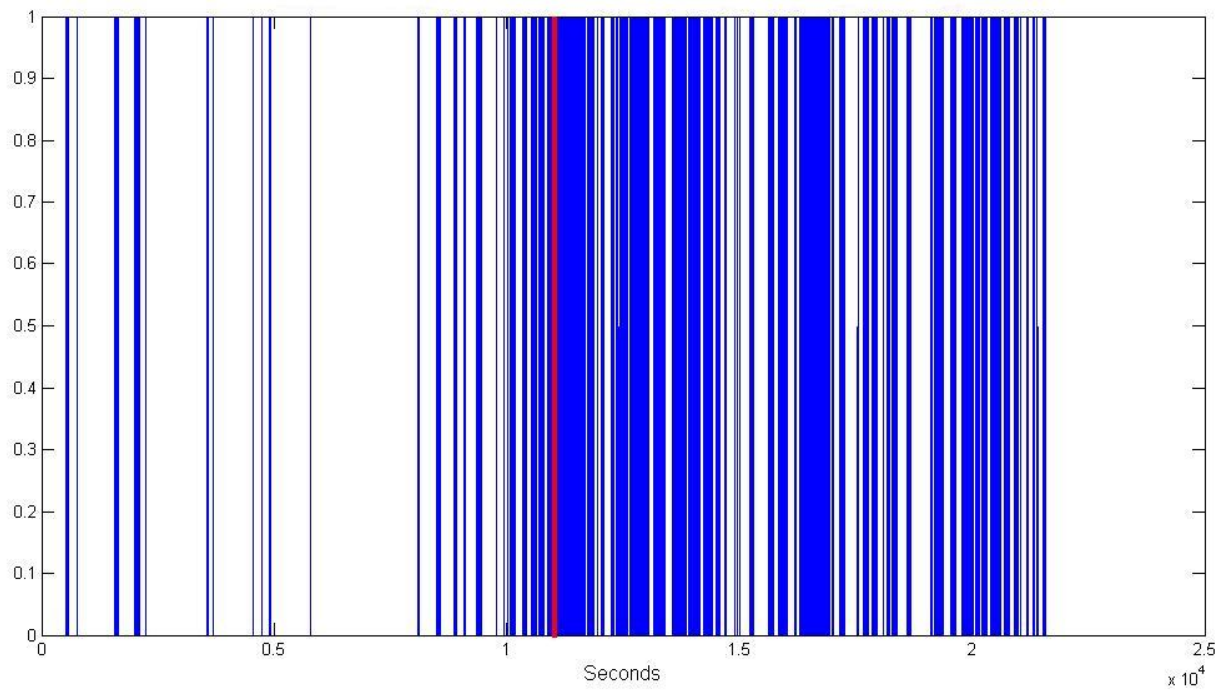

Figure 5. Volatility of volatility clusters. The clusters are depicted by vertical lines, each line corresponding to one cluster.Vertical axis is dimensionless, horizontal axis is time in seconds (three hours prior to 3 hours after the nonfarm payroll release). Release occured at second 10,800 . Note that the number of clusters increases notably subsequent to the release. 

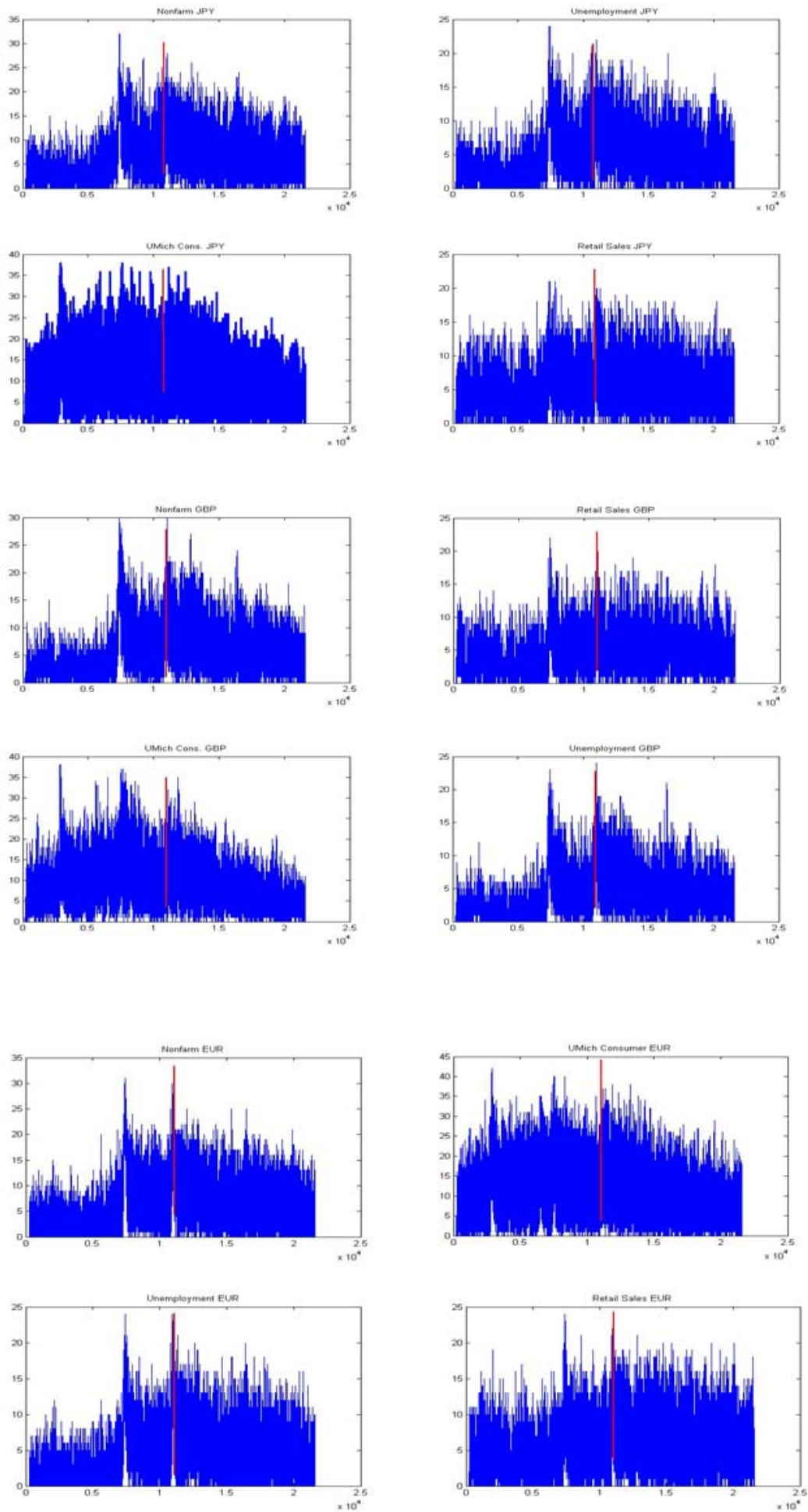

Figure 6. Volatility of volatility clusters. Clusters are depicted by vertical lines, with each line corresponding one cluster. Vertical axis is the number of days with volatility cluster at a particular second; horizontal axis is the time in seconds. Release occurred at second 10,800 . 

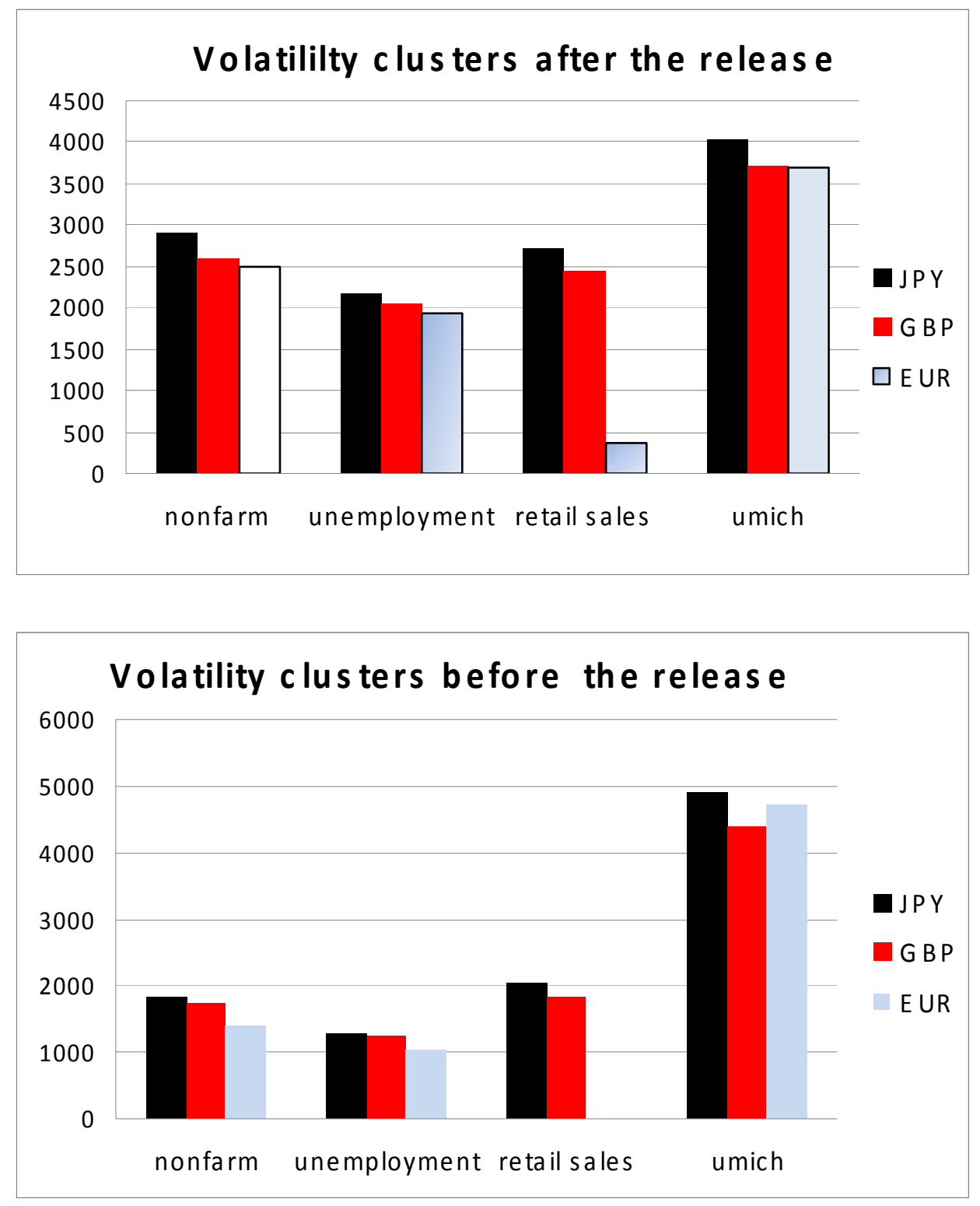

Figure 7: Volatility clustering before and after four representative releases. Vertical axis is the number of minutes (three hours prior to release, and three hours after the release) with volatility clusters in four years of data. The releases are nonfarm payroll, unemployment, retail sales and University of Michigan Consumer Confidence survey. 

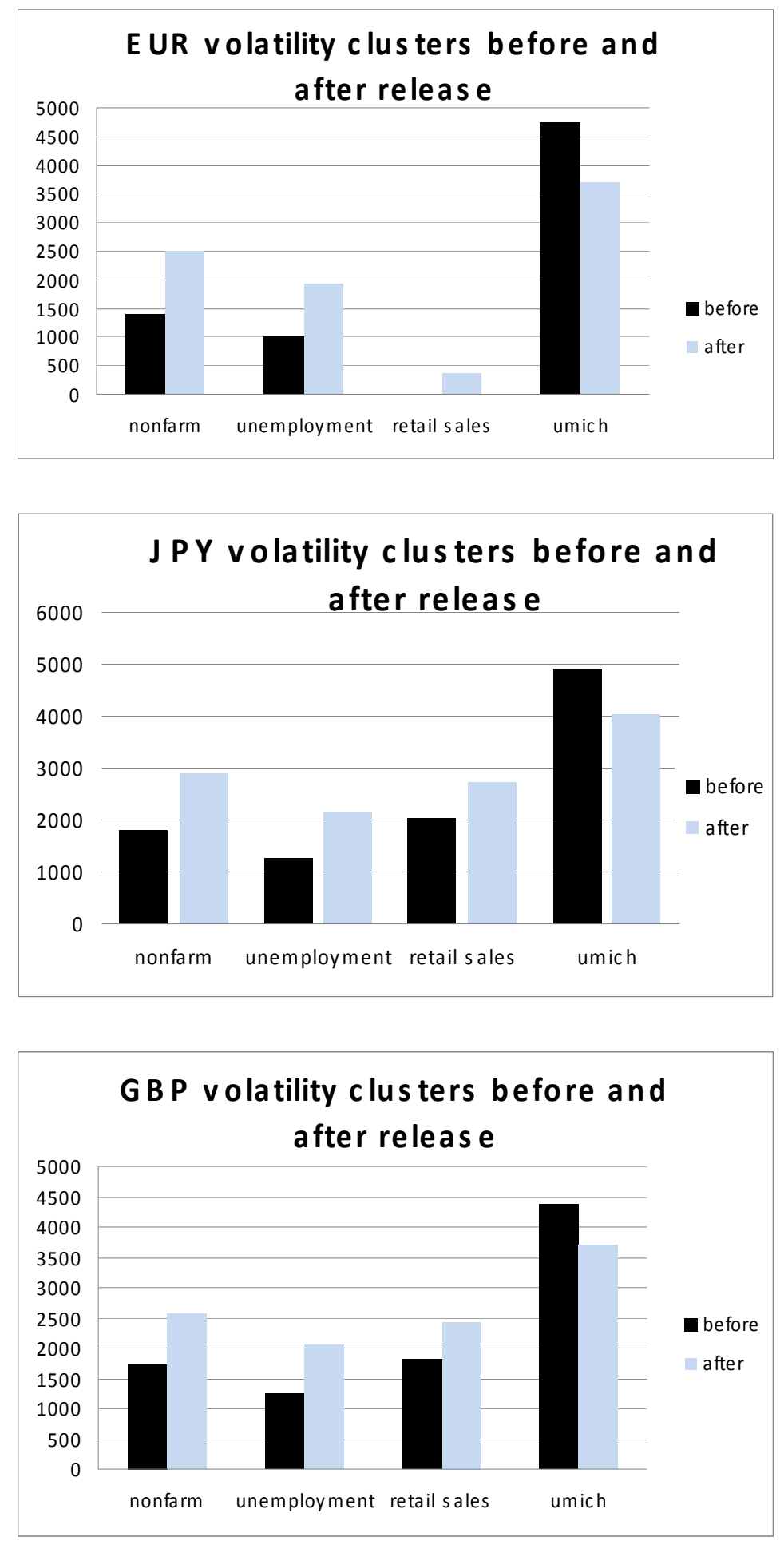

Figure 8 . Volatility clustering comparison between three major currencies. Vertical axis is the number of minutes with volatility clusters in four years of data (three hours prior to three hours after the release). The releases are nonfarm payroll, unemployment, retail sales and University of Michigan Consumer Confidence survey. 


\section{Working Paper Series in Economics}

recent issues

No. 3 Omid Rezania, Svetlozar T. Rachev, Edward Sun, Frank J. Fabozzi: Analysis of the intraday effects of economic releases on the currency market, August 2010

No. 2 Young Shin Kim, Svetlozar T. Rachev, Michele Leonardo Bianchi, Ivan Mitov, Frank J. Fabozzi: Time series analysis for financial market meltdowns, August 2010

No. 1 Biliana Güner, Svetlozar T. Rachev, Daniel Edelman, Frank J. Fabozzi: Bayesian inference for hedge funds with stable distribution of returns, August 2010 